\title{
Chronic Hypertension and Altered Baroreflex Responses in Transgenic Mice Containing the Human Renin and Human Angiotensinogen Genes
}

\author{
David C. Merrill, $\|$ Mark W. Thompson, ${ }^{\S}$ Cayla L. Carney, ${ }^{\|}$Bruno P. Granwehr, ${ }^{\star \ddagger}$ Gunther Schlager, ${ }^{\Uparrow}$ Jean E. Robillard, ${ }^{\S}$ \\ and Curt D. Sigmund ${ }^{\star \neq}$ \\ Departments of *Internal Medicine, ${ }^{\ddagger}$ Physiology and Biophysics, ${ }^{\S}$ Pediatrics, and ${ }^{\|}$Obstetrics and Gynecology, University of Iowa College \\ of Medicine, Iowa City, Iowa 52242; and "Division of Biological Sciences, Genetics Program, University of Kansas, \\ Lawrence, Kansas 66045
}

\begin{abstract}
We have generated a transgenic model consisting of both the human renin and human angiotensinogen genes to study further the role played by the renin-angiotensin system in regulating arterial pressure. Transgenic mice containing either gene alone were normotensive, whereas mice containing both genes were chronically hypertensive. Plasma renin activity and plasma angiotensin II levels were both markedly elevated in the double transgenic mice compared with either single transgenic or nontransgenic controls. The elevation in blood pressure caused by the human transgenes was independent of the genotype at the endogenous renin locus and was equal in mice homozygous for the Ren-1 ${ }^{\mathrm{c}}$ allele or in mice containing one copy each of Ren-1 $1^{\mathrm{c}}$, Ren-1 $\mathbf{1}^{\mathrm{d}}$, or Ren-2. Chronic overproduction of angiotensin II in the double transgenic mice resulted in a resetting of the baroreflex control of heart rate to a higher pressure without significantly changing the gain or sensitivity of the reflex. Moreover, this change was not due to the effects of elevated pressure itself since angiotensin-converting enzyme inhibition had minimal effects on the baroreflex in spontaneously hypertensive BPH-2 control mice, which exhibit non-renindependent hypertension. This double transgenic model should provide an excellent tool for further studies on the mechanisms of hypertension initiated by the renin-angiotensin system. (J. Clin. Invest. 1996. 97:1047-1055.) Key words: renin-angiotensin system - high blood pressure transgenic mice $\bullet$ genetics $\bullet$ cardiovascular regulation
\end{abstract}

\section{Introduction}

The renin-angiotensin system (RAS) ${ }^{1}$ is well recognized as an important factor in the control of arterial pressure through nu-

Address correspondence to Curt D. Sigmund, Ph.D., Director, Transgenic Animal Facility, Departments of Medicine \& Physiology, 6-432 Bowen Science Building, University of Iowa, Iowa City, IA 52242. Phone: 319-335-7828; FAX: 319-335-7330; E-mail: curt-sigmund@ uiowa.edu

Received for publication 6 September 1995 and accepted in revised form 30 November 1995.

1. Abbreviations used in this paper: ACE, angiotensin-converting enzyme; EKG, electrocardiogram; hAng, human angiotensinogen; hRen, human renin; MABP, mean arterial blood pressure; MAP, mean arterial pressure; PRA, plasma renin activity; RAS, reninangiotensin system.

J. Clin. Invest.

(C) The American Society for Clinical Investigation, Inc.

0021-9738/96/02/1047/09 \$2.00

Volume 97, Number 4, February 1996, 1047-1055 merous physiological, molecular biological, and molecular genetic studies. The obvious nature of the RAS as a candidate system for the etiology of hypertension has prompted a number of investigators to examine this system at the molecular biologic and molecular genetic level, and several important findings have resulted from these studies. First, the levels of mRNAs encoding renin, angiotensinogen, and angiotensinconverting enzyme (ACE) are significantly altered in some tissues of experimentally hypertensive and genetically hypertensive rats when compared with their normotensive counterparts (1-5). Second, centrally administered antisense oligonucleotides to angiotensinogen are effective in lowering blood pressure in spontaneously hypertensive rats (6). Finally, genetic studies have been reported that suggest that the renin, angiotensinogen, and ACE genes may be linked or associated with blood pressure in humans and genetically hypertensive rats (710). These data, along with studies demonstrating that ACE inhibitors are effective antihypertensive agents even in patients or hypertensive animals with normal or low plasma renin activity (11), suggest the RAS not only plays an important role in blood pressure regulation in renin-dependent hypertensive individuals but also in patients suffering from non-renindependent hypertension.

The use of transgenic and other genetically manipulated animal models created by gene targeting have become important tools to unravel the complex interplay of genetic and environmental influences causing essential hypertension in humans. Indeed, recent advances in our ability to record reproducibly sophisticated physiological parameters in small genetically manipulatable animals have helped to overcome obvious constraints and limitations of performing genetic analysis in humans and should complement ongoing genetic studies on human populations. We have previously described two transgenic mouse models that separately contain and express the human renin (hRen) and human angiotensinogen (hAng) genes in a tissue-specific manner $(12,13)$. In the present study, we report the generation of a double transgenic mouse model in which lifelong expression of both the hRen and hAng genes results in chronic hypertension and altered arterial baroreflex control of heart rate.

\section{Methods}

\section{Experimental mice}

Transgenic mice. Transgenic mice carrying both the hRen and hAng genes $\left(\mathrm{R}^{+} / \mathrm{A}^{+}\right)$were generated by breeding heterozygous $\mathrm{hRen}$ transgenic mice with heterozygous hAng transgenic mice. Approximately $25 \%$ of the offspring from this breeding were double transgenic, and there was no apparent increased mortality in the $\mathrm{R}^{+} / \mathrm{A}^{+}$mice. We used hRen transgenic line 9 and hAng transgenic line 204/1 in the generation of the double transgenic mice. Both transgenic lines have 
been previously described in detail (12-14). Double transgenic mice were identified by PCR of genomic DNA purified from tail biopsy samples using hRen and hAng specific primers as previously described $(12,13)$.

BPH-2 mice. Spontaneously hypertensive BPH-2 mice were maintained at both the University of Kansas and University of Iowa Animal Care Units. A small BPH-2 mouse colony was established in Iowa by brother-sister mating of several breeding pairs obtained from the Kansas colony. The original derivation of the BPH-2 strain has been described previously $(15,16)$.

Mouse husbandry. All mice were fed standard mouse chow and water ad libitum. Care of the mice used in the experiments met or exceeded the standards set forth by the National Institutes of Health in their guidelines for the care and use of experimental animals. All procedures were approved by the University Animal Care and Use Committee at the University of Iowa.

\section{Analysis of nucleic acids}

Southern blot analysis. Southern blot analysis was used to genotype the double transgenic animals at the mouse renin locus. A PvuII restriction fragment-length polymorphism was used to differentiate between the endogenous Ren- $1^{\mathrm{c}}$, Ren- $1^{\mathrm{d}}$, and Ren- 2 genes from the hRen transgene. $10 \mu \mathrm{g}$ of genomic DNA from tail biopsy samples was electrophoresed on $0.8 \%$ agarose gels and transferred to nylon-supported nitrocellulose membranes as previously described (13). Genomic DNA isolated from the livers of C57BL/6J (Ren-1/Ren-1 ${ }^{\mathrm{c}}$ ) and B6SJL [C57BL/6J $\times$ SJL/J F $F_{1}$ ] (Ren- $1^{\mathrm{c}}$, Ren- $1^{\mathrm{d}}$, Ren-2) was used as a control. The blots were hybridized with a random primer labeled partial Ren-2 cDNA using standard protocols (17). The identification of the mouse renin alleles was as previously described $(18,19)$, and the identification of the hRen transgene bands were confirmed using purified hRen transgene DNA as a control (data not shown).

RNAse protection assay. Expression of hRen and hAng mRNA was confirmed in the liver and kidney using an RNase protection assay. The probes were a partial hRen cDNA from coordinates 741 to 1148 cloned into pSL301 (Invitrogen, San Diego, CA), a partial hAng cDNA from coordinates 302 to 840 cloned into pCRII (Invitrogen) after PCR amplification of a section of exon II (13), and a partial mouse $\beta$-actin cDNA provided by the manufacturer (Ambion Inc., Austin, TX). Total RNA was isolated from liver and kidney samples by homogenization in guanidine isothiocyanate followed by phenol emulsion extraction at $\mathrm{pH} 4.0$ using a modification (20) of the method previously described (21). Homogenizations were scaled up to $2.5 \mathrm{ml}$ to increase RNA yield and quality. 10- $\mu \mathrm{g}$ samples of total tissue RNA were hybridized to single-stranded labeled antisense RNA probes generated by T3 (hRen) or SP6 (hAng and actin) polymerases using the Maxiscript Kit (Ambion, Inc.). RNase protection was as described by the manufacturer. Protection products were visualized by electrophoresis through 5\% acrylamide-8-M urea sequencing gels that were fixed and dried for autoradiography.

\section{Surgical preparation}

For chronic catheterization, mice were anesthetized with Avertin (0.2-0.3 ml, intraperitoneally), shaved, and prepped with a $70 \%$ alcohol solution. Sterile femoral artery and vein catheters (Microrenathane; Braintree Laboratories, Braintree, MA, 0.040 outer diameter $\times 0.025$ inner diameter) were inserted with the aid of a dissecting microscope as described (13). Catheters were flushed with a sterile dilute heparin solution $(10 \mathrm{U} / \mathrm{ml})$ and tunneled subcutaneously to the neck. Small sterile copper wires, attached directly on the right and left thoracic muscles and tunneled under the skin to the neck, were used for heart rate determination via electrocardiogram (EKG) monitoring. The mice were placed on a warming pad $\left(39^{\circ} \mathrm{C}\right)$ throughout the surgical procedure and postoperatively until fully awake. All animals were given a prophylactic dose of antibiotics (penicillin G, 12,000 U i.m.) on the day of the surgery. At least $24-48 \mathrm{~h}$ of recovery were allowed before any experimental manipulation.

\section{Experimental protocols}

Serial baseline blood pressure measurement. On each of four consecutive days, the mice $\left(\mathrm{R}^{+} / \mathrm{A}^{+} n=5, \mathrm{R}^{+} / \mathrm{A}^{-} n=4\right)$ were placed in a small restraining tube, and the catheters were flushed with the dilute heparin solution. The mice were allowed to rest comfortably in the tube for 30-45 min before beginning any measurements. Systolic, diastolic, and mean arterial pressure were measured with a standard pressure transducer (Sorenson; Abbott Laboratory, North Chicago, IL) connected to a Hewlett-Packard (HP) blood pressure monitoring system. Heart rate was determined by an HP cardiotachometer triggered from the pressure pulse signal. Arterial pressure and heart rate were sampled at $0.2 \mathrm{~Hz}$ for $1 \mathrm{~h} / \mathrm{d}$ and recorded on line with an HP computer (model 486-33) using Labtech Notebook (Version 4.2; Laboratory Technologies, Wilmington, MA).

Evaluation of baroreflex sensitivity. The mice $\left(\mathrm{R}^{+} / \mathrm{A}^{+} n=10\right.$, $\left.\mathrm{R}^{-} / \mathrm{A}^{-} n=11, \mathrm{BPH}-2 n=10\right)$ were placed in the restraining tube, the catheters were flushed, and a 30-45-min rest period was allowed (as above). Mean arterial pressure was measured as outlined above. In these studies, heart rate was determined by means of an HP EKG monitor from the EKG leads previously implanted. This allowed for accurate recording of heart rate even with narrowing of the pulse pressure. Arterial baroreflex control of heart rate was determined by producing acute changes in mean arterial blood pressure (MABP) with ramp intravenous infusion $(0.03 \mathrm{ml}$ over $2 \mathrm{~min})$ of phenylephrine (0.1-3 mg/100 g body wt) and nitroprusside (0.1-3 mg/100 g body wt) using an infusion pump (Harvard Apparatus, Inc., S. Natick, MA). The order of administration of each drug was randomized to eliminate bias. A 15-min recovery period was allowed for arterial pressure and heart rate to return to baseline values before administering the next drug. After control baroreflex curves were generated, all mice were given the ACE inhibitor enalapril $(0.250 \mathrm{mg} / 0.2 \mathrm{ml})$, intravenously at a dose we have previously found to completely block the pressor response to angiotensin I (dose $2.0 \mu \mathrm{g} / 0.1 \mathrm{ml}$ ). Administration of an identical volume of saline does not alter baseline arterial pressure in normal mice (data not shown). After administration of enalapril, a 30-min equilibration period was allowed. Baroreflex curves after enalapril were then determined in an identical fashion as during the control period. Heart rate and arterial pressure were sampled at $4.0 \mathrm{~Hz}$ during baroreflex curve determinations.

The different baroreflex curves expressed as the relationship between MABP and heart rate (HR) were analyzed using a logistic sigmoid function according to the following equation:

$H R=P_{4}+\left[P_{1} /\left(1+\exp \left[P_{2}\left(\mathrm{MABP}-P_{3}\right)\right]\right)\right]$

where $P_{1}$ is the range between the upper and lower plateaus, $P_{2}$ is a coefficient to calculate the gain as a function of pressure, $P_{3}$ is the MABP at midrange of the curve (midpoint), and $P_{4}$ is the lower plateau (22). The gain was calculated from the first derivative of the above equation (22). The threshold pressure (lowest pressure that produces a significant decline in heart rate) and saturation pressure (pressure necessary to achieve maximal inhibition of heart rate) were calculated from the third derivative of the equation (22).

\section{Endocrinology}

Plasma renin activity. Double transgenic $\left(\mathrm{R}^{+} / \mathrm{A}^{+}\right)$, single transgenic $\left(\mathrm{R}^{+} / \mathrm{A}^{-}, \mathrm{R}^{-} / \mathrm{A}^{+}\right)$, and nontransgenic $\left(\mathrm{R}^{-} / \mathrm{A}^{-}\right)$control littermates were killed by $\mathrm{CO}_{2}$ asphyxiation. Approximately $0.5 \mathrm{ml}$ of fresh blood was collected from the aorta and placed in chilled tubes containing $2.5 \mu \mathrm{l}$ of 0.5 -M EDTA. The specimen was immediately spun in a prechilled centrifuge at $14 \mathrm{~K}$ for $5 \mathrm{~min}$, and a $150-\mu \mathrm{l}$ plasma sample was obtained and immediately frozen at $-80^{\circ} \mathrm{C}$ until radioimmunoassays were performed using the RIANEN ${ }^{125} \mathrm{I}$-angiotensin radioimmunoassay kit (DuPont, Wilmington, DE) using the directions and reagents supplied by the manufacturer. All samples were frozen and thawed once. Plasma samples were thawed in an ice bath. Once thawed, $2 \mu \mathrm{l}$ of dimercaprol, $2 \mu \mathrm{l}$ of 8 -hydroxyquinoline, and $200 \mu \mathrm{l}$ of maleate buffer were added to $100 \mu$ l of plasma (all reagents were obtained with the radioimmunoassay kit). Samples were split into two 
tubes. Tube A contained $200 \mu \mathrm{l}$ of sample and was incubated at $0^{\circ} \mathrm{C}$. Tube B contained $100 \mu \mathrm{l}$ of the sample and was incubated at $37^{\circ} \mathrm{C}$. Samples were incubated for $1 \mathrm{~h}$. Radioimmunoassay was then performed according to the protocol supplied by the manufacturer. Samples were appropriately diluted with reagent blank so that the radioimmunoassay results were on the linear portion of the standard curve. The amount of angiotensin I generated in each sample was obtained by comparison with a standard curve generated each time the assay was performed. Plasma renin activity was determined by subtracting the amount of angiotensin I generated $/ \mathrm{ml}$ per $\mathrm{h}$ in the $0^{\circ} \mathrm{C}$ sample from the amount generated in the $37^{\circ} \mathrm{C}$ sample.

Angiotensin II levels. Plasma samples were obtained from double transgenic, single transgenic, and nontransgenic controls as previously described. Radioimmunoassay was performed using ${ }^{125} \mathrm{I}$-angiotensin II radioimmunoassay kit (Peninsula Laboratories, Inc., Belmont, CA) using the directions and reagents supplied by the manufacturer. All samples were frozen and thawed once. Plasma samples were thawed in an ice bath. Samples were appropriately diluted with RIA buffer supplied by manufacturer to ensure that radioimmunoassay results were on the linear portion of the standard curve. Diluted plasma samples were incubated with $100 \mu$ l of rabbit anti-angiotensin II peptide overnight at $4^{\circ} \mathrm{C}$. After overnight incubation, $\sim 15,000 \mathrm{cpm}$ of ${ }^{125} \mathrm{I}$-angiotensin II was diluted in $100 \mu \mathrm{l}$ RIA buffer and added to samples. Samples were again incubated overnight at $4^{\circ} \mathrm{C}$. After overnight incubation, $100 \mu$ l of goat anti-rabbit IgG serum and $100 \mu$ l of normal rabbit serum were added to reaction mix. Samples were then incubated for $90 \mathrm{~min}$ at room temperature. $500 \mu \mathrm{l}$ of RIA buffer was then added, and samples were centrifuged at 3,000 rpm for $20 \mathrm{~min}$. The supernatant was poured off, and samples were counted in a gamma scintillation counter. The amount of angiotensin II present in each plasma sample was determined by comparison with a standard curve generated each time the assay was performed.

\section{Statistics and data analysis}

Data analysis between different groups of animals was performed by one-way ANOVA. If the F statistic was significant $(P<0.05)$, then comparison among means was performed using the Newman-Keuls test (23). We considered $P$ values $<0.05$ statistically significant. All values are expressed as the mean \pm SEM.

\section{Results}

Transgenic mice containing the hRen and hAng genes were previously constructed to develop models to investigate tissuespecific and cell-specific regulation of the human genes. The hRen transgenic mice consisted of a genomic construct containing all exons and introns with 892 bp of $5^{\prime}$ flanking DNA and 400 bp of $3^{\prime}$ flanking DNA. Previous studies revealed that active hRen is released into the systemic circulation and that the regulation of hRen mRNA in the kidney was responsive to angiotensin II feedback mechanisms (12). The hAng mice were similarly constructed with a genomic construct containing all five exons and introns with $1.2 \mathrm{~kb}$ of $5^{\prime}$ flanking DNA and $1.5 \mathrm{~kb}$ of $3^{\prime}$ flanking DNA (13). Biochemical studies revealed that hAng was released in abundance into the systemic circulation achieving levels 150-fold greater than that found in human plasma. Blood pressure measurements made in conscious mice revealed that hAng mice responded to a single bolus dose of hRen by raising blood pressure $40 \mathrm{mmHg}$ over $2 \mathrm{~min}$. The response was blocked by pretreating mice with an ACE inhibitor.

Development of double transgenic mouse model (hRen/ hAng). hRen and hAng mice were cross-bred to develop a mouse model of chronic hypertension that could provide a tool to study the role played by the RAS in the development and maintenance of hypertension. Breeding studies clearly showed that $25 \%$ of the mice from a cross of heterozygous hRen and hAng mice were doubly transgenic and that there was no increased mortality in the double transgenic animals.

To confirm that both the hRen and hAng genes were expressed in the double transgenic mice, RNase protection assays were performed on total RNA isolated from kidney and liver of $\mathrm{hRen} / \mathrm{hAng}$ double transgenic mice $\left(\mathrm{R}^{+} / \mathrm{A}^{+}\right)$and nontransgenic $\left(\mathrm{R}^{-} / \mathrm{A}^{-}\right)$controls (Fig. 1). In kidney, both hRen and hAng mRNA expression was evident in $\mathrm{R}^{+} / \mathrm{A}^{+}$mice. In liver, only hAng mRNA was evident in $\mathrm{R}^{+} / \mathrm{A}^{+}$mice. Both results are consistent with the tissue specificity of the human transgenes as previously reported $(12,13)$. No expression of either transgene was evident in the nontransgenic controls, demonstrating the specificity and sensitivity of the assay.

Baseline blood pressure measurements. Direct intraarterial blood pressure measurements were made in a group of $\mathrm{R}^{+} / \mathrm{A}^{+}$ $(n=5)$ and hRen single transgenic control $\left(\mathrm{R}^{+} / \mathrm{A}^{-}, n=4\right)$ mice using an indwelling femoral arterial catheter. The mice in these experiments were conscious but restrained in plastic animal holders. Systolic, mean, and diastolic pressure was recorded for $1 \mathrm{~h}$ each day for four consecutive days after allowing a 24-h recovery period after surgery (Fig. 2). In $\mathrm{R}^{+} / \mathrm{A}^{+}$ mice, mean arterial pressure (MAP) ranged from 150.6 \pm 5.0 to $159.2 \pm 6.7 \mathrm{mmHg}$ and did not vary significantly during the $4 \mathrm{~d}$ of measurement. In control $\left(\mathrm{R}^{+} / \mathrm{A}^{-}\right)$mice, MAP ranged from $111.1 \pm 4.1$ to $116.1 \pm 4.9 \mathrm{mmHg}$. Similar elevations in both systolic and diastolic blood pressure were observed in $\mathrm{R}^{+} / \mathrm{A}^{+}$ mice. In contrast, no significant difference in heart rate was noted between groups (Fig. 2). In addition, there was no significant difference in the blood pressures of $\mathrm{R}^{-} / \mathrm{A}^{-}, \mathrm{R}^{+} / \mathrm{A}^{-}$, and single $\mathrm{hAng}$ transgenic $\left(\mathrm{R}^{-} / \mathrm{A}^{+}\right)$mice (data not shown). These results clearly demonstrate that mice chronically expressing both the hRen and hAng genes become chronically hypertensive.

Plasma renin activity and angiotensin II measurements. Measurements of plasma renin activity (PRA) in each of four groups of mice $\left(\mathrm{R}^{+} / \mathrm{A}^{+}, \mathrm{R}^{+} / \mathrm{A}^{-}, \mathrm{R}^{-} / \mathrm{A}^{+}, \mathrm{R}^{-} / \mathrm{A}^{-}\right)$is depicted in Fig. $3 A$. PRA was noted to be significantly elevated in $\mathrm{R}^{+} / \mathrm{A}^{+}$

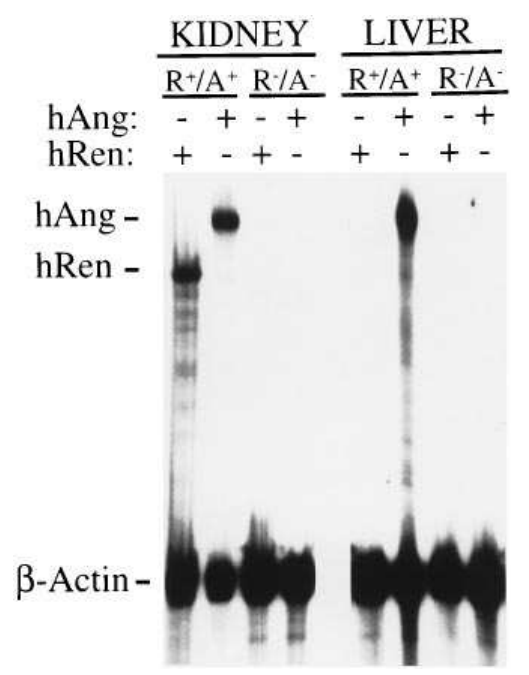

Figure 1. Expression of hRen and hAng in kidney and liver. RNase protection assay was used to assay for hRen and hAng mRNAs in kidney and liver of $\mathrm{R}^{+} /$ $\mathrm{A}^{+}$and $\mathrm{R}^{-} / \mathrm{A}^{-}$mice. The genotype of the animals examined is shown at the top of the figure. Each lane contained a $\beta$-actin control probe and either an $\mathrm{hAng}$ or hRen probe as indicated above each lane. The position of the protection products obtained with each probe is indicated. Exposure time is $3 \mathrm{~d}$. 

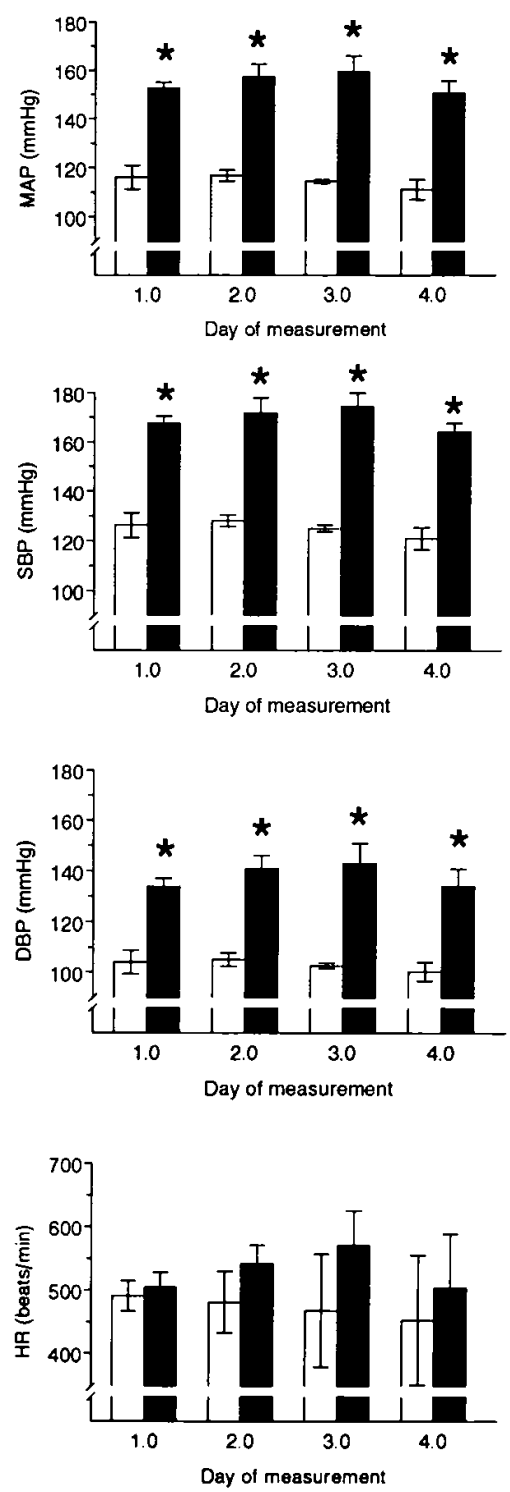
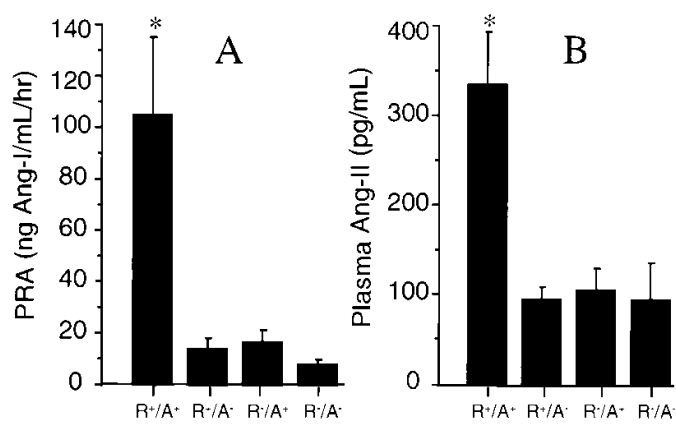

Figure 3. Plasma renin activity and angiotensin II levels in hypertensive and normotensive mice. (A) PRA of $\mathrm{R}^{+} / \mathrm{A}^{+}(n=8), \mathrm{R}^{+} / \mathrm{A}^{-}(n=$ $8), \mathrm{R}^{-} / \mathrm{A}^{+}(n=4)$, and $\mathrm{R}^{-} / \mathrm{A}^{-}(n=5)$ mice is shown. PRA assays were performed as described in Methods. $* P<0.05 \mathrm{vs}^{-} / \mathrm{A}^{-}$. (B) Plasma angiotensin II concentration in $\mathrm{R}^{+} / \mathrm{A}^{+}(n=8), \mathrm{R}^{+} / \mathrm{A}^{-}(n=$ $4), \mathrm{R}^{-} / \mathrm{A}^{+}(n=5)$, and $\mathrm{R}^{-} / \mathrm{A}^{-}(n=4)$ mice is shown and was measured as described in Methods. $* P<0.02$ vs $\mathrm{R}^{-} / \mathrm{A}^{-}$.

Genotyping at renin locus. Previous reports have clearly demonstrated that there is a large range of variability in blood pressure among different inbred strains of mice (16). In addition, the mouse exhibits an interesting polymorphism at the renin locus in that some strains contain two renin genes (Ren- $1^{\mathrm{d}}$ and Ren-2) while others contain a single renin gene (Ren- $\left.1^{c}\right)$ (18). The Ren- $1^{\mathrm{c}}$ and Ren- $1^{\mathrm{d}}$ genes are allelic while the Ren-2 gene is the result of a recent duplication at the renin locus $(28$, 29). Although there is no defined correlation between blood pressure and the genotype at the renin locus, we were concerned that since the mice used in this study were derived from an $\mathrm{F}_{2}$ population of $\mathrm{C} 57 \mathrm{BL} / 6$, which contains the Ren- $1^{\mathrm{c}}$ gene, and SJL/J, which contains the Ren- $1^{\mathrm{d}}$ and Ren- 2 genes, that random segregation of the different renin alleles may be responsible for the blood pressure differences seen in Fig. 2. Therefore, to ensure the results were not artificially derived from the polymorphism at the mouse renin locus, we genotyped each animal in the experiment described in Fig. 2. Fig. 4 depicts the genotyping at the renin locus for the nine mice used in the baseline blood pressure protocol. In addition, the MAP over the $4 \mathrm{~d}$ of monitoring is shown. As can be seen, each mouse genotyped as either Ren- $1^{\mathrm{c}} / \operatorname{Ren}-1^{\mathrm{c}}$ or as $\operatorname{Ren}-1^{\mathrm{c}}$ / Ren-1/Ren-2. Importantly, mice representative of each genotype were equally distributed among the $\mathrm{R}^{+} / \mathrm{A}^{+}$and $\mathrm{R}^{+} / \mathrm{A}^{-}$ mice studied (four $\mathrm{R}^{+} / \mathrm{A}^{+}$mice and three $\mathrm{R}^{+} / \mathrm{A}^{-}$mice each had a single copy of Ren- $1^{\mathrm{c}}, \operatorname{Ren}-1^{\mathrm{d}}$, and Ren-2, and one $\mathrm{R}^{+} / \mathrm{A}^{+}$and $\mathrm{R}^{+} / \mathrm{A}^{-}$mouse each were homozygous for the Ren- $1^{c}$ allele). Hypertension in these animals clearly segregates with the presence of both the hRen and hAng genes and not with the presence or absence of any particular mouse renin gene or allele, further confirming that the elevated blood pressure observed in these animals was due to the interaction of the human proteins.

Baroreflex control of heart rate. Studies examining the arterial baroreflex control of heart rate were conducted in three separate groups of animals: The first group consisted of $\mathrm{R}^{+} / \mathrm{A}^{+}$ double transgenic mice $(n=10)$. The second group consisted of nonhypertensive $\mathrm{R}^{-} / \mathrm{A}^{-}$control mice $(n=11)$. The third group consisted of spontaneously hypertensive inbred mice (BPH-2, $n=10)$ previously described by Schlager $(15,16)$. The BPH-2 mice are chronically hypertensive. This strain was derived from a genetically selected high blood pressure line by 


\begin{tabular}{rrrrrrrrrrrr} 
Mouse & 1 & 2 & 3 & 4 & 5 & 6 & 7 & 8 & 9 & $\mathrm{CxS}$ & $\mathrm{C}$ \\
hRen & + & + & + & + & + & + & + & + & + & - & - \\
hAng & + & + & - & - & + & - & + & - & + & - & - \\
\hline
\end{tabular}

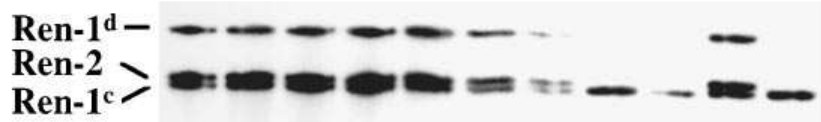
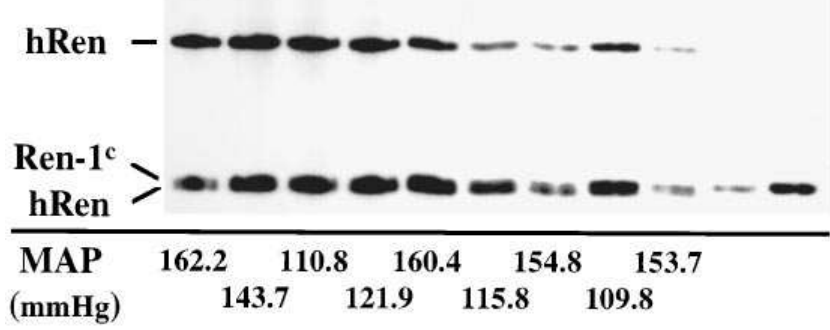

Figure 4. Genotype at the mouse renin locus in $\mathrm{R}^{+} / \mathrm{A}^{+}$and $\mathrm{R}^{+} / \mathrm{A}^{-}$ mice. RFLP analysis was performed to genotype $\mathrm{R}^{+} / \mathrm{A}^{+}$and $\mathrm{R}^{+} / \mathrm{A}^{-}$ at the mouse renin locus. $10 \mu \mathrm{g}$ of genomic DNA isolated from tail biopsies (transgenics) or liver (CXS and C) was digested with PvuII and Southern blotted and probed as described in Methods. The nine mice shown here are same as used in Fig. 2. The presence of the hRen and $\mathrm{hAng}$ transgenes is indicated above each lane. The average value over the 4-d protocol for MAP is shown below each lane. The position of the different mouse renin alleles and the hRen gene is indicated. $C, \mathrm{C} 57 \mathrm{BL} / 6 \mathrm{~J} ; C X S,[\mathrm{C} 57 \mathrm{BL} / 6 \mathrm{~J} \times \mathrm{SJL} / \mathrm{J}] \mathrm{F}_{2}$.

brother/sister inbreeding (15). The original base population from which the high blood pressure selection was initiated was the result of an eight-way cross of inbred mouse strains with varying levels of blood pressure (16). The BPH-2 strain is now completely inbred and is thought to exhibit a non-renindependent mode of hypertension (30).

A representative example of a baroreflex curve demonstrating the sigmoidal curve relationship between MAP and heart rate in a mouse is presented in Fig. 5. Results of baroreflex responses in these strains are depicted in Figs. 6 and 7 and the parameters of the baroreflex are shown in Table I. Heart rate responses to acute changes in arterial pressure (induced with phenylephrine and nitroprusside infusions) were determined both before and after angiotensin converting enzyme blockade (enalapril) in all three groups of mice. Before ACE blockade, there were no significant differences between groups for the gain of the baroreflex responses $\left(\mathrm{R}^{+} / \mathrm{A}^{+}=\right.$ $\left.-17.2 \pm 4.2, \mathrm{R}^{-} / \mathrm{A}^{-}=-16.0 \pm 2.6, \mathrm{BPH}-2=-17.5 \pm 5.5\right)$. In contrast, threshold, saturation, and midpoint pressures were all significantly higher in $\mathrm{R}^{+} / \mathrm{A}^{+}$mice than in either of the two groups, thus signifying a parallel right shift of the sigmoid baroreflex curve (Fig. 7). With ACE blockade, no significant change in the gain or sensitivity of the baroreflex curve was noted in any of the three groups. There was, however, a significant shift to the left in the baroreflex curve in $\mathrm{R}^{+} / \mathrm{A}^{+}$mice, as threshold, saturation, and midpoint pressure were all significantly lower after enalapril. No change, however, was noted in either the maximum or minimum parameters with enalapril in $\mathrm{R}^{+} / \mathrm{A}^{+}$mice.

In $\mathrm{R}^{-} / \mathrm{A}^{-}$mice, enalapril resulted in a small decrease in saturation and midpoint without statistically significant decreases in threshold, minimum, or maximum responses. Similar changes were observed with enalapril in BPH-2 mice; namely, a slight yet significant decrease in saturation and midpoint without significant differences in gain, threshold, minimum, or maximum responses. Of note is the fact that, after enalapril treatment, the midpoint of the baroreflex curve of $\mathrm{R}^{+} / \mathrm{A}^{+}$mice was still significantly higher than that of $\mathrm{R}^{-} / \mathrm{A}^{-}$mice but was not significantly different than that of BPH-2 mice. In addition, after enalapril treatment, the baseline blood pressure of $\mathrm{R}^{+} / \mathrm{A}^{+}$ mice $(114.7 \pm 5.1 \mathrm{mmHg})$ was significantly higher than that of control mice $(90.0 \pm 4.2 \mathrm{mmHg})$ but was similar to that observed in BPH-2 mice $(116.6 \pm 5.1 \mathrm{mmHg})$.

\section{Discussion}

In the present study, we report a transgenic mouse model in which lifelong overexpression of both hRen and hAng genes results in chronic hypertension and resetting of the arterial baroreflex control of heart rate to a higher pressure. This is the first report demonstrating the existence of arterial baroreflex control of heart rate in the mouse and its response to elevated blood pressure and angiotensin II.

Generation and analysis of the hRen/hAng transgenic model. This model was created by cross-breeding of mice transgenic for a genomic clone encoding hRen with those transgenic for a genomic clone encoding hAng. The hRen mice are characterized by tissue-specific expression of human renin in the kidney and extrarenal sites that normally express renin

Table I. Parameters of Baroreflex Control of Heart Rate

\begin{tabular}{|c|c|c|c|c|c|c|}
\hline & \multicolumn{2}{|c|}{$\mathrm{R}^{-} / \mathrm{A}^{-}(n=11)$} & \multicolumn{2}{|c|}{$\mathrm{R}^{+} / \mathrm{A}^{+}(n=10)$} & \multicolumn{2}{|c|}{ BPH-2 $(n=10)$} \\
\hline & -ENAL & +ENAL & -ENAL & +ENAL & -ENAL & +ENAL \\
\hline Gain & $-16.0 \pm 2.6$ & $-18.8 \pm 3.1$ & $-17.2 \pm 4.2$ & $-17.7 \pm 4.0$ & $-17.5 \pm 5.5$ & $-21.3 \pm 5.3$ \\
\hline Minimum & $295.5 \pm 18.4$ & $319.3 \pm 30.1$ & $319.4 \pm 40.3$ & $298.0 \pm 31.4$ & $260.8 \pm 19.8$ & $233.4 \pm 16.4$ \\
\hline Maximum & $694.4 \pm 15.6$ & $669.5 \pm 27.3$ & $640.9 \pm 19.8$ & $640.8 \pm 32.6$ & $599.9 \pm 21.4$ & $574.6 \pm 34.6$ \\
\hline Saturation & $144.1 \pm 4.4$ & $125.0 \pm 5.9 *$ & $181.4 \pm 8.5$ & $156.3 \pm 7.0 *$ & $156.5 \pm 3.6$ & $144.0 \pm 2.7^{*}$ \\
\hline Threshold & $107.8 \pm 4.7$ & $98.7 \pm 4.1$ & $150.0 \pm 8.5$ & $126.0 \pm 7.1 *$ & $121.1 \pm 6.4$ & $116.0 \pm 5.9$ \\
\hline Midpoint & $125.9 \pm 3.5$ & $111.9 \pm 4.7 *$ & $165.6 \pm 8.1$ & $141.1 \pm 6.6^{*}$ & $138.8 \pm 4.1$ & $129.9 \pm 3.2^{\ddagger}$ \\
\hline Baseline MAP & $113.1 \pm 2.8$ & $90.0 \pm 4.2 *$ & $138.4 \pm 7.5$ & $114.7 \pm 5.1 *$ & $133.4 \pm 2.5$ & $116.6 \pm 5.1 *$ \\
\hline Baseline HR & $626.3 \pm 30.1$ & $656.6 \pm 29.9$ & $621.7 \pm 25.0$ & $621.7 \pm 34.8$ & $492.9 \pm 30.5$ & $483.0 \pm 36.9$ \\
\hline
\end{tabular}

Parameters that were used to develop the baroreflex curves in Fig. 6 are shown. $* P<0.006,{ }^{\ddagger} P<0.03$ vs pre-enalapril-treated group. 


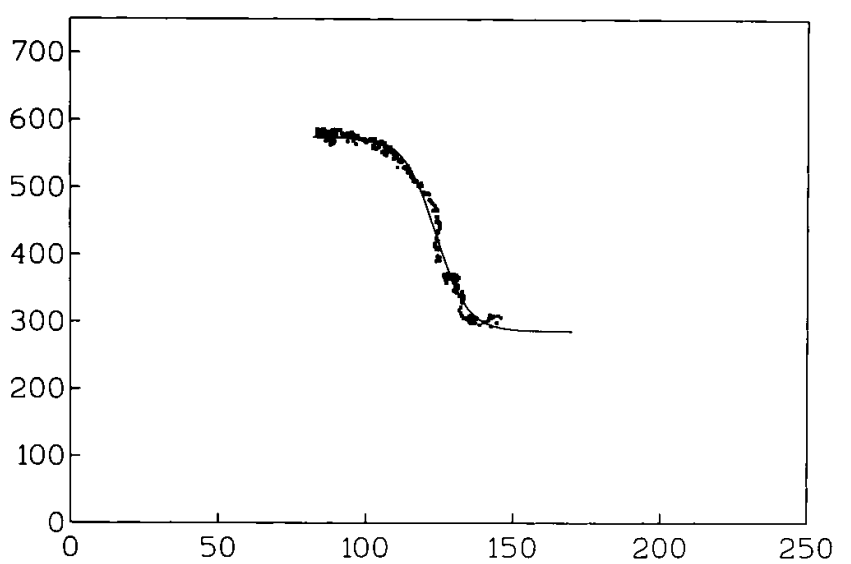

Figure 5. Baroreflex control of heart rate. A representative example of a baroreflex curve for an individual mouse. All dots represent individual data points collected at a rate of $4.0 \mathrm{~Hz}$ during generation of baroreflex curves with phenylephrine and nitroprusside infusions. The best-fit sigmoid baroreflex curve generated as described above is also depicted.

mRNA (12). The level of hRen mRNA in the kidney was approximately equal to or slightly lower than the endogenous renin mRNA and was therefore not "overexpressed." Recent experiments to assess the level of circulating human renin suggest that active human renin is present in the circulation but at levels lower than circulating active mouse renin. In contrast to this, hAng mRNA in both the kidney and liver of $\mathrm{R}^{-} / \mathrm{A}^{+}$mice is clearly overexpressed, achieving levels in great abundance over the endogenous angiotensinogen mRNA. We have determined (13) that plasma hAng levels in the $\mathrm{R}^{-} / \mathrm{A}^{+}$ single transgenic mice are $>230 \mu \mathrm{g} / \mathrm{ml}$, which is $\sim 150$-fold higher than the concentration of hAng in normal human plasma (10).
Previous work in our laboratory and others has clearly demonstrated that there is a strict species specificity to the renin-angiotensinogen reaction between mouse and human such that hRen does not proteolytically cleave mouse angiotensinogen, and mouse renin does not cleave hAng (13, 24-26). Therefore, it was not surprising that single transgenic $\mathrm{R}^{+} / \mathrm{A}^{-}$ and $\mathrm{R}^{-} / \mathrm{A}^{+}$mice had normal plasma renin activities, and plasma angiotensin II levels and were normotensive. Nevertheless, administration of a single bolus dose of purified human renin to hAng mice resulted in an acute pressor response, which is sensitive to pretreatment with an ACE inhibitor (13).

The presence of low levels of active human renin in combination with excess circulating hAng produced a three to fourfold elevation in circulating angiotensin II, which was sufficient to cause a sustained increase in arterial pressure. Kim and co-workers $(31,32)$ demonstrated that small increases in the level of circulating mouse angiotensinogen in gene-targeted mice containing three and four copies of the endogenous angiotensinogen gene were sufficient to cause a dramatic elevation in blood pressure. Our results along with those of Kim and co-workers $(31,32)$ strongly support the contention that genetic abnormalities resulting in increased expression of angiotensinogen can result in elevated blood pressure. These results are consistent with the molecular genetic studies of Jeunemaitre et al (10), in which linkage between the angiotensinogen locus and hypertension and an increased incidence of hypertension in patients with elevated levels of plasma angiotensinogen was reported. The data are also consistent with the findings of increased angiotensinogen expression in some tissues of hypertensive rats (4) and the abrogation of hypertension in rats by central administration of antisense oligonucleotides to angiotensinogen (6).

Ohkubo et al. (33) previously reported elevated systolic blood pressure in transgenic mice containing both the rat renin and rat angiotensinogen genes. As in our experiments, trans-

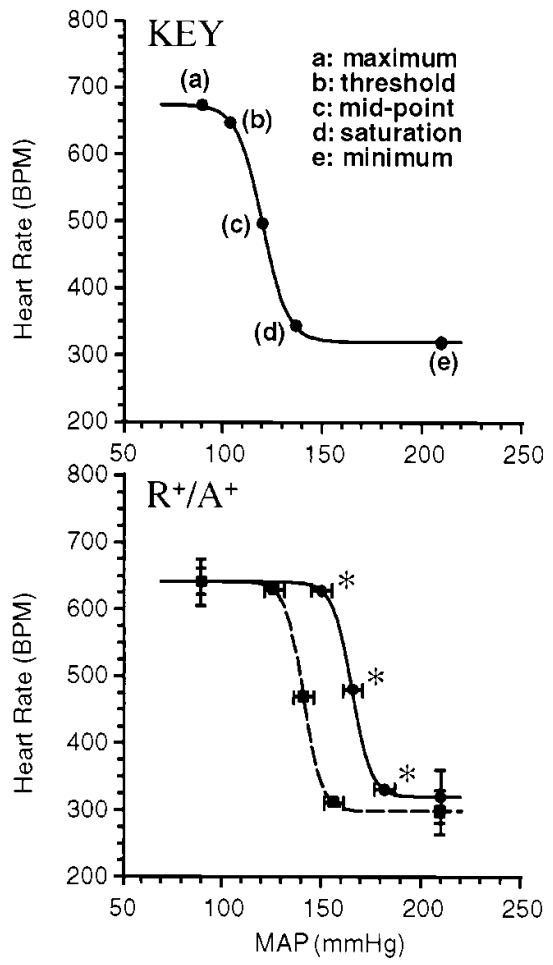

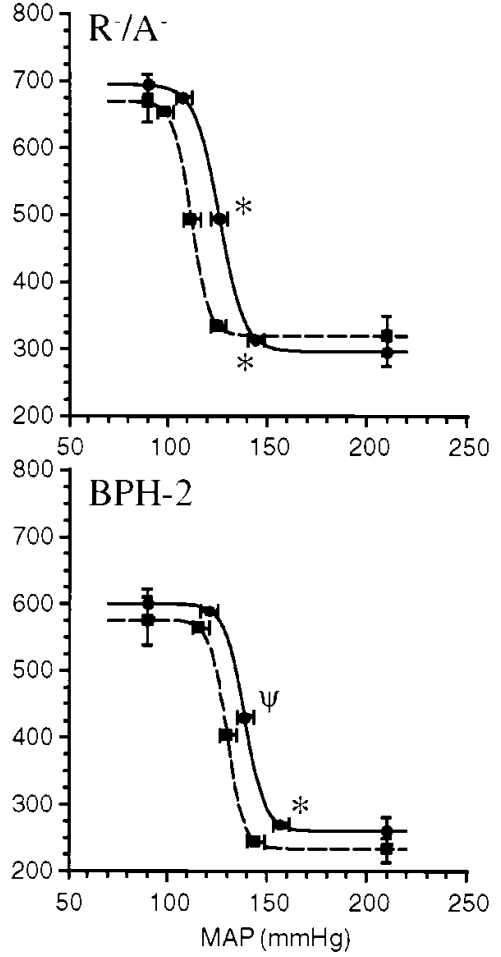

Figure 6. Baroreflex control of heart rate in double transgenic and spontaneously hypertensive mice. Composite baroreflex curves and baroreflex parameters for control $\mathrm{R}^{-} / \mathrm{A}^{-}, \mathrm{R}^{+} / \mathrm{A}^{+}$, and $\mathrm{BPH}-2$ mice are depicted. Responses before (solid line) and after enalapril (dashed line) are shown. Baroreflex parameters depicted are shown on the key. ( $\_$- B ) Before enalapril treatment; (--- ) after enalapril treatment. All values are expressed as mean \pm SEM. $* P<$ $0.006,{ }^{\psi} P<0.03$ when comparing pre vs post enalapril values. 


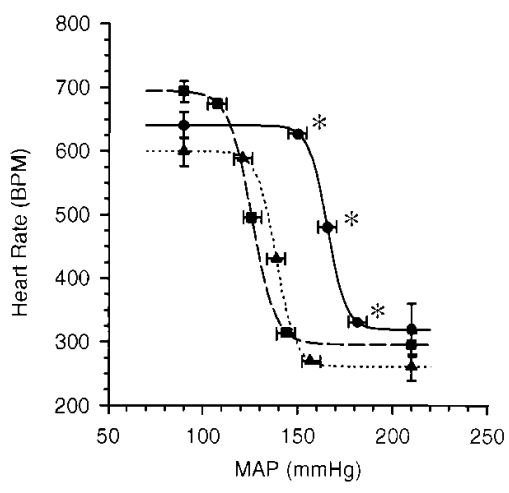

are shown. ( $\longrightarrow-(-) \mathrm{R}^{+} / \mathrm{A}^{+} ;(--\mathbf{-}-)$ control mice; $(-\boldsymbol{-}--)$ BPH-2 mice. All values are expressed as mean \pm SEM. $* P<0.001$ when comparing $\mathrm{R}^{+} / \mathrm{A}^{+}$with either $\mathrm{R}^{-} / \mathrm{A}^{-}$or $\mathrm{BPH}-2$ mice.

genic mice containing either gene, but not both genes, exhibited normal blood pressure. They used transgenes consisting of a fusion between the metallothionein promoter and the coding region of either renin or angiotensinogen. This resulted in unregulated expression of rat renin and angiotensinogen mRNA in the liver, the major site of metallothionein promoter activity, and constitutive release of both proteins into the systemic circulation. These results suggest that the species specificity of the human and mouse renin-angiotensinogen reaction we and others have observed both in vivo and in vitro $(13,26,34,35)$ also exists when comparing mouse with rat. However, these results conflict with other in vivo studies demonstrating that transgenic mice containing the rat angiotensinogen gene, but not the rat renin gene, are chronically hypertensive (36), and transgenic rats containing a mouse renin gene are severely hypertensive (37). Moreover, biochemical studies demonstrate that rat angiotensinogen is not only an excellent substrate for mouse renin but is cleaved with enhanced kinetics (38). It is interesting to note that one expectation from the Ohkubo study was that, since the renin transgene was expressed in the liver and not kidney, the major form of renin released would be prorenin. Since renin activity measurements were not performed, it remains unclear how much prorenin was processed to active renin in their transgenic animals. Our experiments use clones of human renin and human angiotensinogen encoded in genomic constructs containing their endogenous promoters. Consequently, we expected and demonstrated that the genes would be $(a)$ expressed only in tissues that normally transcribe renin or angiotensinogen mRNA in adult mice (12, 13) and during development (14); (b) that human renin, because of its juxtaglomerular cell origin, would be processed to active renin (12); and (c) that species specificity of the human renin-angiotensinogen reaction would allow us to develop a model of chronic hypertension when both genes were present.

Arterial baroreflex regulation of heart rate in $h R e n / h A n g$ mice. Despite the fact that double transgenic mice containing the hRen and hAng genes are chronically hypertensive, there was no significant difference in the heart rate of control normotensive and transgenic hypertensive mice. Therefore, to determine if there are any potential alterations in the relationship between heart rate and arterial pressure in this mouse model, baroreflex curves were generated in nontransgenic control mice and double transgenic $\left(\mathrm{R}^{+} / \mathrm{A}^{+}\right)$hypertensives.
Previous studies (39-41) have examined the acute effects of increased endogenous or exogenous angiotensin II on the arterial baroreflex. The present study is the first to examine the effects of lifelong genetic overexpression of angiotensin II on the arterial baroreflex. We found that chronic overproduction of angiotensin II resulted in a right shift (resetting) of the baroreflex curve to a higher pressure level without alterations in the gain or sensitivity of the reflex. This resetting of the baroreflex does not appear to be secondary to the elevated arterial pressure itself since minimal effects of ACE inhibition were noted in the spontaneously hypertensive mouse (BPH-2), which is thought to be a renin-independent model of hypertension (30). Further support for a pressure-independent influence of angiotension II on baroreflex resetting comes from recent work by Brooks (42). She demonstrated that angiotensin-induced baroreflex resetting was partially reversed soon after angiotension II infusion was stopped despite maintenance of the hypertensive state with infusions of phenylephrine or methoxamine. Although the exact mechanism of baroreflex resetting by angiotension II is unknown, it is thought to involve central nervous system actions via AT- 1 receptors at the level of the area postrema $(43,44)$.

The present results in conscious mice are in accord with many previous studies performed in a variety of species in which angiotensin II has been shown to result in a resetting (right shift) of the baroreceptor reflex control of heart rate (43, 45). Controversy continues to exist, however, concerning the effect of angiotensin II on the gain or sensitivity of baroreflex control of heart rate. Some investigators $(40,46,47)$ have reported that angiotensin II decreases baroreflex sensitivity and that blockade of the RAS increases the gain. Others, however, have reported resetting without a change in gain $(43,45)$. The reasons for these differences are unclear but may involve differences in the species studied, use of anesthesia, or dose of angiotensin II used. In the conscious rabbit, acute infusions of angiotensin II have been reported to have minimal influences on baroreflex gain $(44,48)$. However, Guo and Abboud (40) reported that angiotensin II attenuated the heart rate response to phenylephrine. In this study, though, the rabbits were studied in the anesthetized state, and relatively large doses of angiotensin II were used (400 ng/kg per min). Brooks (42) noted that chronic infusions of angiotensin II in conscious rabbits resulted in resetting of the baroreflex control of heart rate and a decrease in baroreflex gain. Potential species differences are demonstrated by the fact that angiotensin II has been reported to decrease the gain of the baroreflex in conscious sheep (46) and baboons (47) but not in conscious dogs (45).

Mechanisms of hypertension in hRen/hAng transgenic mice. Since the $\mathrm{hRen} / \mathrm{hAng}$ double transgenic mice clearly exhibit increased circulating levels of angiotensin II, it is likely that the pressor actions of angiotensin II are at least initially responsible for the development of hypertension in the model. However, it is important that we do not rule out other possible mechanisms that may be responsible for the maintenance of lifelong hypertension. Indeed, activation of the RAS could result in alterations in arterial pressure through a number of mechanisms, such as: $(a)$ direct hemodynamic and vascular effects, $(b)$ alterations in central sympathetic outflow, $(c)$ stimulation of aldosterone biosynthesis and therefore sodium retention, or $(d)$ through intrarenal actions of angiotensin II on sodium reabsorption or local hemodynamics. It is of interest that both the midpoint of the baroreflex curve and baseline 
blood pressure were still significantly higher in $\mathrm{R}^{+} / \mathrm{A}^{+}$mice (versus control $\mathrm{R}^{-} / \mathrm{A}^{-}$mice) after ACE blockade. One may suggest, therefore, that in addition to the effects of the RAS, other mechanisms such as structural remodeling of the vessel walls, chronic resetting of the arterial baroreflex, and changes in other vascular regulatory systems may be contributing to the maintenance of hypertension in $\mathrm{R}^{+} / \mathrm{A}^{+}$mice.

The activation of intrinsic tissue RAS may also play a role in the initiation and maintenance of high blood pressure in the hRen/hAng mice. The activation of tissue RAS has been implicated in the mechanism of hypertension in transgenic rats containing the mouse renin gene (49). Although the concept of tissue RAS remains controversial, the evidence for a physiologically important role for an intrinsic RAS in the kidney at least is compelling. For example, mRNA encoding renin, angiotensinogen, ACE, AT-1 receptor, and AT-2 receptor, along with each RAS protein, has been detected and localized at the cellular level in the kidney (50-54). In the present model, we have demonstrated both hRen and hAng mRNAs in the kidney (Fig. 1). Furthermore, we have previously localized the expression of hRen and hAng by in situ hybridization to the renal juxtaglomerular cells (12) and the proximal convoluted tubule cells (13), respectively. Physiological and pharmacological studies have suggested that the intrarenal RAS plays an important role in regulating renal blood flow and hemodynamics, tubuloglomerular feedback, and sodium excretion (55-57); and the intrarenal effects of angiotensin II in regulating renal sodium may be quantitatively more important than extrarenal effects (58). Kidney renin is the major source of circulating renin and proteolytically cleaves liver-derived angiotensinogen in the systemic circulation. However, since the initial release of juxtaglomerular cell-synthesized renin is into the interstitial space (59) and its level in renal lymph has been reported to be 10-20-fold greater than in plasma (60), angiotensin I may be directly formed from angiotensinogen synthesized and released from renal proximal convoluted tubule cells. The functional significance of this local production remains unclear because the proportion of angiotensin-I derived from locally synthesized versus circulating angiotensinogen has yet to be measured accurately. Nevertheless, since hemodynamic changes within the glomerular microcirculation can occur rapidly, and angiotensin II has been reported to influence both mesangial cell (61) and efferent arteriolar constriction (62), the hypothesis that angiotensin II can be generated and regulated locally becomes very attractive.

Summary and perspectives. In summary, we report a transgenic mouse model in which lifelong overexpression of both hRen and hAng genes results in chronic hypertension and chronic resetting of the arterial baroreflex control of heart rate. Further studies are ongoing to elucidate the relative contribution of intrarenal versus extrarenal actions of angiotensin II on the maintenance of hypertension in this mouse model. The mouse continues to be an important species in cardiovascular research. This unique model lends itself to both genetic and physiologic manipulations that could potentially elucidate mechanisms of hypertension not previously possible using traditional models.

\section{Acknowledgments}

We thank Robin Davisson, Gongyu Yang, Shane Smith, Julie Lang, Norma Sinclair, and Lucinda Robbins for technical assistance associ- ated with generation and characterization of transgenic mice. We also thank Dr. Mark Chapleau for his critical review of the manuscript, and Ruth Hurlbert and Fay Burdick for their secretarial assistance. Transgenic mice were generated and maintained at the University of Iowa Transgenic Animal Facility, which is supported in part by the College of Medicine and the Diabetes and Endocrinology Research Center.

Funds to support the work described were provided by the National Institutes of Health (HL48058 to C.D. Sigmund, DK38302 and DK43961 to J.E. Robillard), American Heart Association (to C.D. Sigmund and D.C. Merrill), Baxter Healthcare Corporation (to C.D. Sigmund), and the Wyeth Pediatric Neonatology Research Fund (to M.W. Thompson). C.D. Sigmund is an Established Investigator of the American Heart Association.

\section{References}

1. Miller, C.C.J., N.J. Samani, A.T. Carter, J.I. Brooks, and W.J. Brammar. 1989. Modulation of mouse renin gene expression by dietary sodium chloride intake in one-gene, two-gene and transgenic animals. J. Hypertens. 7:861-863.

2. Samani, N.J., N.P. Godfrey, J.A. Major, W.J. Brammar, and J.D. Swales. 1989. Kidney renin mRNA levels in the early and chronic phases of two-kidney, one clip hypertension in the rat. J. Hypertens. 7:105-112.

3. Samani, N.J., W.J. Brammar, and J.D. Swales. 1991. Renal and extrarenal levels of renin mRNA in experimental hypertension. Clin. Sci. (Lond.). 80:339-344.

4. Yongue, B.G., J.A. Angulo, B.S. McEwen, and M.M. Myers. 1991. Brain and liver angiotensinogen messenger RNA in genetic hypertensive and normotensive rats. Hypertension (Dallas). 17:485-491.

5. Nishimura, M., A. Milsted, C.H. Block, K.B. Brosnihan, and C.M. Ferrario. 1992. Tissue renin-angiotensin systems in renal hypertension. Hypertension (Dallas). 20:158-167.

6. Gyurko, R., D. Wielbo, and M.I. Phillips. 1993. Antisense inhibition of $\mathrm{AT}_{1}$ receptor mRNA and angiotensinogen mRNA in the brain of spontaneously hypertensive rats reduces hypertension of neurogenic origin. Regul. Pept. 49:167-174.

7. Rapp, J.P., S.M. Wang, and H. Dene. 1989. A genetic polymorphism in the renin gene of Dahl rats cosegregates with blood pressure. Science (Wash. DC). 243:542-544.

8. Deng, Y., and J.P. Rapp. 1992. Cosegregation of blood pressure with angiotensin converting enzyme and atrial natriuretic peptide receptor genes using Dahl salt-sensitive rats. Nat. Genet. 1:267-272.

9. Kurtz, T.W., L. Simonet, P.M. Kabra, S. Wolfe, L. Chan, and B.L. Hjelle. 1990. Cosegregation of the renin allele of the spontaneously hypertensive rat with an increase in blood pressure. J. Clin. Invest. 85:1328-1332.

10. Jeunemaitre, X., F. Soubrier, Y.V. Kotelevtsev, R.P. Lifton, C.S. Williams, A. Charru, S.C. Hunt, P.N. Hopkins, R.R. Williams, J. Lalouel, and P. Corvol. 1992. Molecular basis of human hypertension: role of angiotensinogen. Cell. 71:169-180.

11. Brunner, H.R., H. Gavras, and A. Waeber. 1979. Oral angiotensin-converting enzyme inhibitor in long-term treatment of hypertensive patients. Ann. Intern. Med. 2:1317-1325.

12. Sigmund, C.D., C.A. Jones, C.M. Kane, C. Wu, J.A. Lang, and K.W. Gross. 1992. Regulated tissue- and cell-specific expression of the human renin gene in transgenic mice. Circ. Res. 70:1070-1079.

13. Yang, G., D.C. Merrill, M.W. Thompson, J.E. Robillard, and C.D. Sigmund. 1994. Functional expression of the human angiotensinogen gene in transgenic mice. J. Biol. Chem. 269:32497-32502.

14. Sigmund, C.D. 1993. Expression of the human renin gene in transgenic mice throughout ontogeny. Pediatr. Nephrol. 7:639-645.

15. Schlager, G. 1974. Selection for blood pressure levels in mice. Genetics. 76:537-549.

16. Schlager, G. 1994. Genetic hypertension in mice. In Handbook of Hypertension. D. Ganten and W. de Jong, editors. Elsevier, Amsterdam. 158-172.

17. Ausubel, F.M., R. Brent, R.E. Kingston, D.D. Moore, J.G. Seidman, J.A. Smith, and K. Struhl. 1989. Current protocols in molecular biology. John Wiley \& Sons, Inc., New York.

18. Piccini, N., J.L. Knopf, and K.W. Gross. 1982. A DNA polymorphism, consistent with gene duplication, correlates with high renin levels in the mouse submaxillary gland. Cell. 30:205-213.

19. Sigmund, C.D., and K.W. Gross. 1990. Differential expression of the murine and rat renin genes in peripheral subcutaneous tissue. Biochem. Biophys. Res. Commun. 173:218-223.

20. Burson, J.M., G. Aguilera, K.W. Gross, and C.D. Sigmund. 1994. Differential expression of angiotensin receptor 1A and 1B in mouse. Am. J. Physiol. 267:E260-E267.

21. Chomczynski, P., and N. Sacchi. 1987. Single-step method of RNA isolation by acid guanidinium thiocyanate-phenol-chloroform extraction. Anal. Bio- 
chem. 161:156-159.

22. Kent, B.B., J.W. Drane, B. Blumenstein, and J.W. Manning. 1972. A mathematical model to assess changes in the baroreceptor reflex. Cardiology. 57:295-310. NJ.

23. Zar, J.H. 1984. Biostatistical Analysis. Prentice-Hall, Englewood Cliffs,

24. Burton, J., and T. Quinn. 1988. The amino-acid residues on the C-terminal side of the cleavage site of angiotensinogen influence the species specificity of the reaction with renin. Biochim. Biophys. Acta. 952:8-12.

25. Oliver, W.J., and F. Gross. 1966. Unique specificity of mouse angiotensinogen to homologous renin. Proc. Soc. Exp. Biol. Med. 122:923-926.

26. Hatae, T., E. Takimoto, K. Murakami, and A. Fukamizu. 1994. Comparative studies on species-specific reactivity between renin and angiotensinogen. Mol. Cell. Biochem. 131:43-47.

27. Skinner, S., J. Bouhnik, H. Huang, M.-F. Gonzalez, J. Ménard, and P. Corvol. 1995. Plasma angiotensin in binephrectomised mice. Clin. Exp. Hypertens. 17:847-860.

28. Abel, K.J., and K.W. Gross. 1990. Physical characterization of genetic rearrangements at the mouse renin loci. Genetics. 124:937-947.

29. Abel, K.J., and K.W. Gross. 1988. Close physical linkage of the murine Ren-1 and Ren-2 loci. Nucleic Acids Res. 16:2111-2126.

30. Iwao, H., N. Nakamura, F. Kim, F. Ikimoto, K. Yamamoto, and G. Schlager. 1984. Renin-angiotensin system in genetically hypertensive mice. Jpn. Circ. J. 48:1270-1279.

31. Smithies, O., and H.-S. Kim. 1994. Targeted gene duplication and disruption for analyzing quantitative genetic traits in mice. Proc. Natl. Acad. Sci. USA. 91:3612-3615.

32. Kim, H., J.H. Krege, K.D. Kluckman, J.R. Hagaman, J.B. Hodgin, C.F. Best, J.C. Jennette, T.M. Coffman, N. Maeda, and O. Smithies. 1995. Genetic control of blood pressure and the angiotensinogen locus. Proc. Natl. Acad. Sci. USA. 92:2735-2739.

33. Ohkubo, H., H. Kawakami, Y. Kakehi, T. Takumi, H. Arai, Y. Yokota, M. Iwai, Y. Tanabe, M. Masu, J. Hata, et al. 1990. Generation of transgenic mice with elevated blood pressure by introduction of the rat renin and angiotensinogen genes. Proc. Natl. Acad. Sci. USA. 87:5153-5157.

34. Fukamizu, A., E. Takimoto, K. Sugimura, T. Hatae, M. Seo, S. Takahashi, F. Sugiyama, N. Kajiwara, K. Yagami, and K. Murakami. 1993. Dependence of angiotensin production in transgenic mice carrying either the human renin or human angiotensinogen genes on species-specific kinetics of the reninangiotensin system. Arzneim. Forsch. 43:222-225.

35. Ganten, D., J. Wagner, K. Zeh, M. Koeller, M. Bader, J.B. Michel, M. Paul, F. Zimmermann, P. Ruf, U. Hilgenfeld, et al. 1992. Species-specificity of renin kinetics in transgenic rats harboring the human renin and angiotensinogen genes. Proc. Natl. Acad. Sci. USA. 89:7806-7810.

36. Kimura, S., J.J. Mullins, B. Bunnemann, R. Metzger, U. Hilgenfeldt, F. Zimmermann, H. Jacob, K. Fuxe, D. Ganten, and M. Kaling. 1992. High blood pressure in transgenic mice carrying the rat angiotensinogen gene. $E M B O$ (Eur. Mol. Biol. Organ.) J. 11:821-827.

37. Mullins, J.J., J. Peters, and D. Ganten. 1990. Fulminant hypertension in transgenic rats harbouring the mouse Ren-2 gene. Nature (Lond.). 344:541-544.

38. Tokita, Y., R. Franco-Saenz, E.M. Reimann, and P.J. Mulrow. 1994. Hypertension in the transgenic rat TGR(mRen-2)27 may be due to enhanced kinetics of the reaction between mouse renin and rat angiotensinogen. Hypertension (Dallas). 23:422-427.

39. Kumagai, K., and I.A. Reid. 1994. Angiotensin II exerts differential actions on renal nerve activity and heart rate. Hypertension (Dallas). 24:451-456.

40. Guo, G.B., and F.M. Abboud. 1984. Angiotensin II attenuates baroreflex control of heart rate and sympathetic activity. Am. J. Physiol. 246:H80H89.

41. Segar, J.L., D.C. Merrill, and J.E. Robillard. 1994. Role of endogenous angiotensin II on resetting of the arterial baroreflex during development. Am. J. Physiol. 266:H52-H59.
42. Brooks, V.L. 1995. Chronic infusion of angiotensin II resets baroreflex control of heart rate by an arterial pressure-independent mechanism. Hypertension (Dallas). 26:420-424.

43. Matsukawa, S., and I.A. Reid. 1990. Role of the area postrema in the modulation of the baroreflex control of heart rate by angiotensin II. Circ. Res. 67:1462-1473

44. Wong, J., L. Chou, and I.A. Reid. 1993. Role of AT1 receptors in the resetting of the baroreflex control of heart rate by angiotensin II in the rabbit. $J$. Clin. Invest. 91:1516-1520.

45. Brooks, V.L., and I.A. Reid. 1986. Interaction between angiotensin II and the baroreceptor reflex in the control of adrenocorticotrophic hormone secretion and heart rate in conscious dogs. Circ. Res. 58:816-828.

46. Lee, W.B., M.J. Ismay, and E.R. Lumbers. 1980. Mechanism by which angiotensin II affects the heart rate of the conscious sheep. Circ. Res. 47:286292.

47. Garner, M.G., A.F. Phippard, P.J. Fletcher, J.M. Maclean, G.G. Duggin, J.S. Horvath, and D.J. Tiller. 1987. Effect of angiotensin II on baroreceptor reflex control of heart rate in conscious baboons. Hypertension (Dallas). 10:628634

48. Reid, I.A., and L. Chou. 1990. Analysis of the action of angiotensin II on the baroreflex control of heart rate in conscious rabbits. Endocrinology. 126: 2749-2756.

49. Bader, M., Y. Zhao, M. Sander, M.A. Lee, J. Bachmann, M. Bohm, B. Djavidani, J. Peters, J.J. Mullins, and D. Ganten. 1992. Role of tissue renin in the pathophysiology of hypertension in TGR(mREN2)27 rats. Hypertension (Dallas). 19:681-686.

50. Gomez, R.A., K.R. Lynch, R.L. Chevalier, N. Wilfong, A. Everett, R.M Carey, and M.J. Peach. 1988. Renin and angiotensinogen gene expression in maturing rat kidney. Am. J. Physiol. 254:F582-F587.

51. Tufro-McReddie, A., J.K. Harrison, A.D. Everett, and R.A. Gomez. 1993. Ontogeny of type 1 angiotensin II receptor gene expression in the rat. $J$. Clin. Invest. 91:530-537.

52. Taugner, R., E. Mannek, R. Nobiling, C.P. Buhrle, E. Hackenthal, D Ganten, T. Inagami, and H. Schroder. 1984. Coexistence of renin and angiotensin II in epitheloid cell secretory granules of rat kidney. Histochemistry. 81: $39-45$.

53. Ingelfinger, J.R., W.M. Zuo, E.A. Fon, K.E. Ellison, and V.J. Dzau. 1990. In situ hybridization evidence for angiotensinogen messenger RNA in the rat proximal tubule. An hypothesis for the intrarenal renin angiotensin system. J. Clin. Invest. 85:417-423.

54. Gomez, R.A., K.R. Lynch, R.L. Chevalier, A.D. Everett, D.W. Johns, N. Wilfong, M.J. Peach, and R.M. Carey. 1988. Renin and angiotensinogen gene expression and intrarenal renin distribution during ACE inhibition. Am. J. Physiol. 254:F900-F906.

55. Levens, N.R., M.J. Peach, and R.M. Carey. 1981. Role of the intrarenal renin-angiotensin system in the control of renal function. Circ. Res. 48:157-167.

56. Hall, J.E. 1991. The renin-angiotensin system: renal actions and blood pressure regulation. Compr. Ther. 17:8-17.

57. Johnston, C.I., B. Fabris, and K. Jandeleit. 1993. Intrarenal renin-angiotensin system in renal physiology and pathophysiology. Kidney Int. 42:S59-S63.

58. Hall, J.E., H.L. Mizelle, and L.L. Woods. 1986. The renin-angiotensin system and long term regulation of arterial pressure. J. Hypertens. 4:387-397.

59. Morgan, T.O., and J. Davis. 1975. Renin secretion at the individual nephron. Pflueg. Arch. Eur. J. Physiol. 359:23-31.

60. Proud, D., S. Nakamura, F.A. Carone, M. Herring, M. Kawamura, T. Inagami, and J.J. Pisano. 1984. The kallikrien-kinin and renin-angiotensin system in the rat renal lymph. Kidney Int. 25:880-885.

61. Schor, N., I. Ichikawa, and B.M. Brenner. 1994. Mechanisms of action of various hormones and vasoactive substances on glomerular ultrafiltration in the rat. Kidney Int. 20:442-451.

62. Hall, J.E. 1986. Regulation of glomerular filtration rate and sodium excretion by angiotensin II. Fed. Proc. 45:1431-1437. 